\title{
High Temperature Creep of MgO Single Crystals with $\langle 100\rangle$ Axis at Low Stresses
}

\author{
Qinli BAO, Kenji OHNISHI*, Yasuhiro TANABE and Eiichì YASUDA \\ Research Laboratory of Engineering Materials, Tokyo Institute of Technology, 4259, Nagatsuta, Midori-ku, Yokohama-shi \\ ${ }^{*}$ Central Research Laboratory, Matsushita Electric Works Ltd., 1048, Kadoma, Kadoma-shi, Osaka 571 \\ マグネシア単結晶の〈100〉方向の低応力域における高温クリープ \\ 包＼cjkstart勤立・大西兼司*・田辺靖博・安田榮一 \\ 東京工業大学工業材料研究所, 227 横浜市緑区長津田町 4259 \\ *松下電工(株)中央研究所，571 大阪府門真市大字門真 1048
}

[Received May 28, 1992; Accepted November 20, 1992]

\begin{abstract}
Creep behavior of $\mathrm{MgO}$ single crystals with $\langle\mathbf{1 0 0}\rangle$ loading axis was investigated over temperature range from $1575^{\circ}$ to $1725^{\circ} \mathrm{C}$ and under compression stresses from 3 to $10 \mathrm{MPa}$. It was found that MgO single crystals had a sigmoidal creep behavior which can be described by Haasen's theory. Dislocation multiplication in which a few dislocation interactions were involved was responsible for the increase in creep rate at the initial stage of deformation. The stress exponents were measured to be about 3.4 at inflection point in sigmoidal creep curve and near 2.2 at steady state. The creep behavior at steady state mainly related to dislocation movement on two orthogonal conjugate $\{110\}\langle 110\rangle$ slip systems. The main barriers to slip were caused by dislocation intersections occurring between two orthogonal $\{110\}$ planes. The deformation at steady state was caused by dislocation gliding which depends on the climb motion. The dislocation substructure formed during creep was examined and the deformation mechanism was discussed.
\end{abstract}

Key-words : $M g O$, High temperature creep, Deformation, Slip

\section{Introduction}

There have been a lot of research efforts toward to understand the creep behavior of magnesium oxide, 1)-5) because of its simple rock salt structure and high temperature applications. Most of these studies have primarily been concentrated on the deformation at a region of high stress, only a limited amount of attention has been given to that at low stresses. ${ }^{6)}$ In fact, however, high temperature applications are mainly involved with long time exposures at relatively low stresses. An understanding of deformation behavior of $\mathrm{MgO}$ crept at high temperature and low stresses is actually important. The present investigation provides an experimental study on the deformation of $\mathrm{MgO}$ single crystals compressed with $\langle 100\rangle$ axis at relatively low stresses. The objective of this study is to identify the creep mechanism. The creep behavior was measured as a function of temperature and stress and explained based on the established models and substructure developed during long-term exposure to stress.

Emphasis was placed on two stages of deformation: "initial stage",7) a region in which creep rate keeps increasing before primary state and the steady state in which creep rate keeps constant.

\section{Experimental procedure}

$\mathrm{MgO}$ single crystals were obtained from Tateho Co., Ltd. (Hyogo, Japan). The impurity of crystals determined by flame emission spectroscopy is listed in Table 1. The initial dislocation density counted from etch pits was about $3 \times 10^{7} / \mathrm{m}^{2}$. All samples had a normal size of $5 \times 5 \times 10(\mathrm{~mm})$ and were chemically polished in orthophosphoric acid at $120^{\circ} \mathrm{C}$ before test, except for two loading ends in order to keep parallelism from damage. A layer about $50 \mu \mathrm{m}$ in thickness on the longitude surfaces was removed.

Constant loading tests were conducted under compression with the loading axis $\langle 100\rangle$ at temperature range from $1575^{\circ}$ to $1725^{\circ} \mathrm{C}$ under stresses between 3 and $10 \mathrm{MPa}$. The precision creep equipment and the details on experimental steps followed were given elsewhere. ${ }^{8}$ ) The entire deformation process was monitored by a computer and a Liner Variable Differential Transformer. From the deformation data stored in the computer the whole creep behaviors characterized by strain-time curve and creeprate-time curves at any time intervals could be accurately known through computer's plotting. Whether the inflection point, between initial stage and primary state, and the steady state were achieved or not was determined from the variations of creep rate $\dot{\varepsilon}$ with time $t,(\mathrm{~d} \dot{\varepsilon} / \mathrm{d} t)$. It should equal to zero at both the inflection point and the steady state. The length of test time was usually longer than 180 h.

Table 1. Impurity concentration in $\mathrm{MgO}$ single crystal (ppm).

\begin{tabular}{|c|c|c|c|c|}
\hline Al & Si & $\mathrm{Ca}$ & $\mathrm{Fe}$ & Na, Mn \\
\hline 650 & 300 & 330 & 70 & $<10$ \\
\hline
\end{tabular}


After the test, every deformed sample was carefully cleft and polished for microstructural observation. Observations by optical microscope were mainly performed on $\{100\}$ using chemical etching technique. ${ }^{6)}$ Transmission electron microscope (TEM) observations were carried out at $200 \mathrm{kV}$ (JEOL-200ES).

\section{Results}

Typical creep behavior for $\mathrm{MgO}$ single crystal is shown in Figs. 1(A) and (B). The creep curves exhibit a sigmoidal type of deformation characteristics which can be roughly divided into three stages.
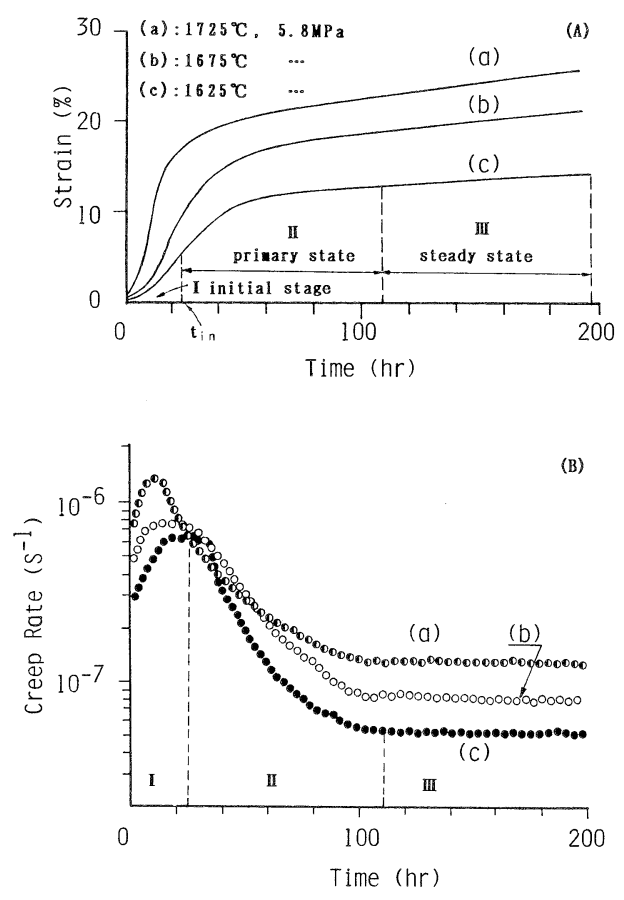

Fig. 1. (A) Creep curves for $\mathrm{MgO}$ single crystals loaded with $\langle 100\rangle$ axis and (B) the variations of creep rate with time at various temperatures under initial stress $5.8 \mathrm{MPa}$.

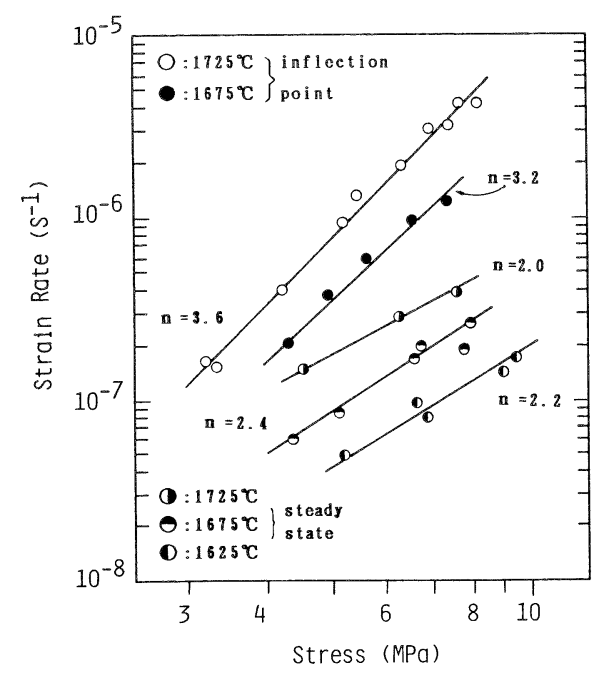

Fig. 2. Stress dependence of creep rate measured at inflection points and at steady state.
Stage I, initial stage, is a region in which creep rate kept increasing with time after loading. Stage II, corresponding to the primary state, consists of a region in which creep rate continuously decreased with time. Between these two stages, there is an inflection point at $t_{\text {in }}$ which is designated as a dividing point of stages I and II. Stage III corresponds to the steady state. The maximum values of the creep rate correspond to the inflection point, and the steady state was approached at about $100 \mathrm{~h}$.

Since the strain at present study is relatively large, in a range of $10-25 \%$, it may cause the change in stress due to the variation of the cross-sectional area supporting the applied load. Therefore, an amendment of the stress has been performed here based on the amounts of strain. The stress dependence of creep rate is summarized in Fig. 2 in a log-log plot. The values of stress exponent $n$ were 3.4 on average at inflection point and about 2.2 at steady state. The temperature dependence of creep rate $\dot{\varepsilon}$ and $t_{\text {in }}{ }^{-1}$ at various stresses is shown by the Arrhenius relation in Figs. 3 and 4, respectively. The apparent activation energies, calculated from the temperature de-

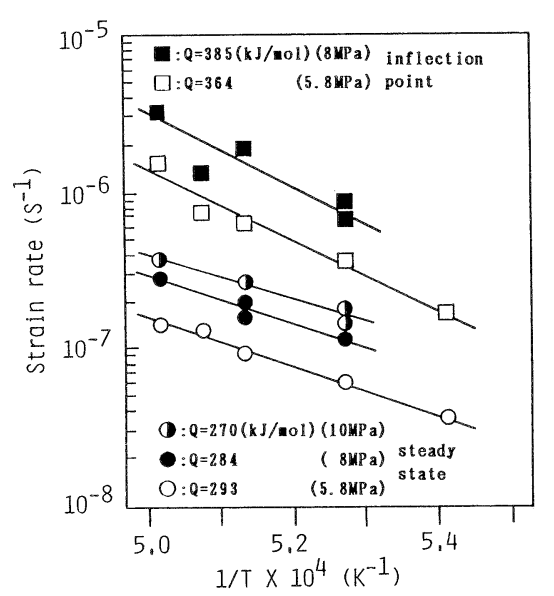

Fig. 3. The temperature dependence of creep rate at inflection points and steady state.

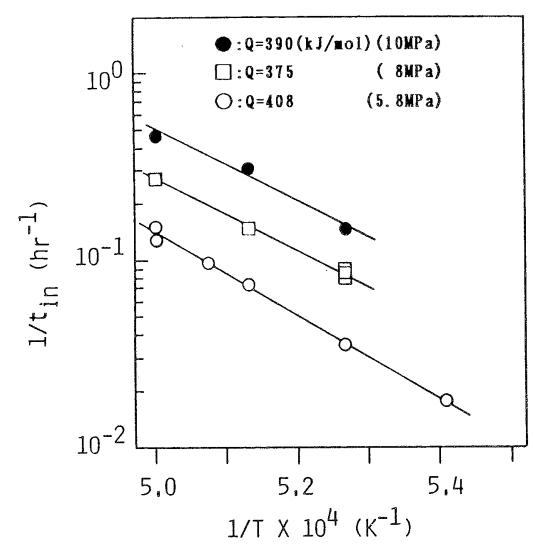

Fig. 4. The temperature dependence of $t_{\text {in }}$ at various initial stresses. 
pendence of $\dot{\varepsilon}$ and $1 / t_{\text {in }}$, were about 375 and $391 \mathrm{~kJ} /$ mol, respectively, at inflection point. The average value obtained at steady state is nearly $282 \mathrm{~kJ} / \mathrm{mol}$. The stress dependence of $t_{\text {in }}$ is given in Fig. 5. The stress exponent $m+n^{\prime}$ for $t_{\text {in }}$ is in a range of $-1.6-$ -1.9 .

At the present stress ranges, it was noticed that with increase in loading stress $\sigma$ the time required to reach inflection point $t_{\text {in }}$ became shorter. For any one creep curve at the present stress range the values of $t / t_{\text {in }}$ can be described by $\varepsilon / \varepsilon_{\text {in }}$ where $\varepsilon$ is the strain at time $t$ and $\varepsilon_{\text {in }}$ is the strain at inflection point. This relation is shown in Fig. 6 by the normalized creep curves obtained at different experimental temperatures.

The shapes of the specimen after creep test are shown in Fig. 7. Apparently, the barreling has taken place during deformation, however, it is only confined to a pair of parallel surfaces. The typical microstructures formed at initial stage near inflection point and steady state are shown in Figs. 8 and 9 , respectively. It is found that at initial stage the dislocations are limited within the straight slip bands. At steady state, on the other hand, the straight slip trances are replaced by the diffuse bands containing a very high density of pits within them. In those slip bands dislocation pile-up, dipoles and cusps are present. The tanglement in dislocation alignment near the intersection points of slip bands is obvious

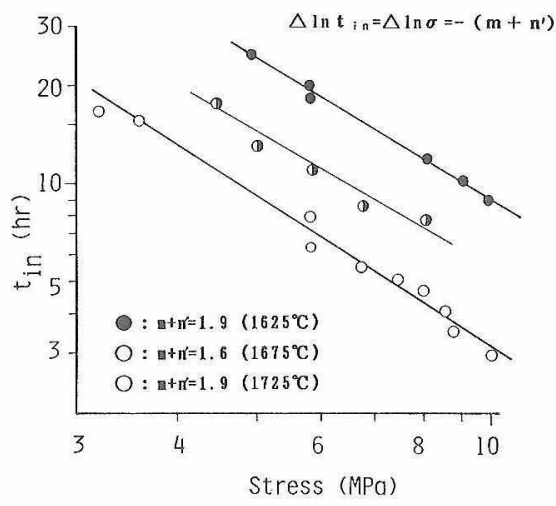

Fig. 5. Stress dependence of the time to inflection point. The value of $m+n^{\prime}$ is the stress exponent of $t_{\text {in }}$ as given in Eq. 3 .

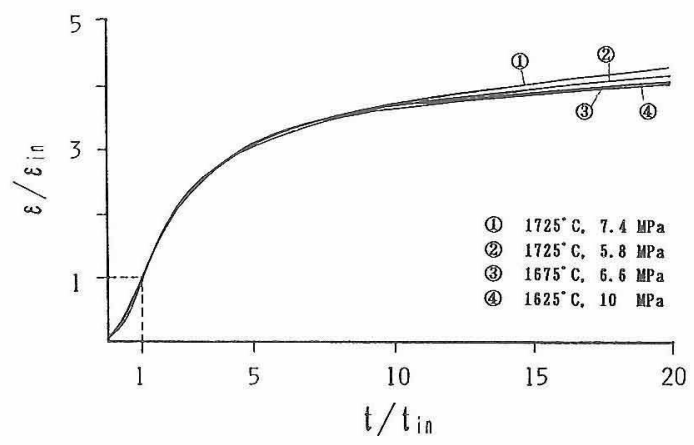

Fig. 6. Normalized strain $\varepsilon / \varepsilon_{\text {in }}$ vs. normalized time $t / t_{\text {in }}$ at various stresses and temperatures.

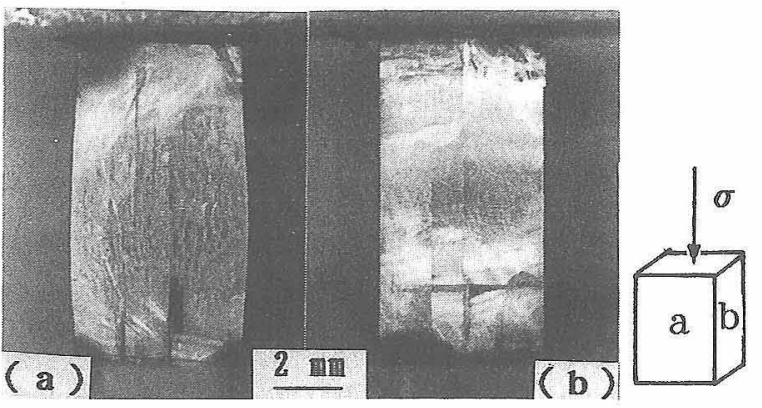

Fig. 7. Specimen crept to $13 \%$ at $1675^{\circ} \mathrm{C}$ under $8 \mathrm{MPa}$ observed on two neighbouring longitudinal surfaces (a) and (b).

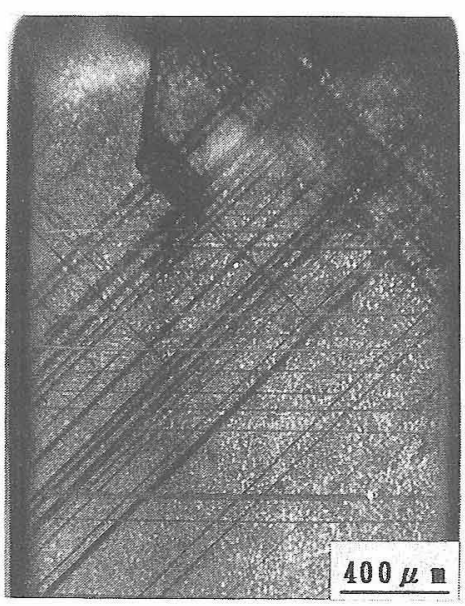

Fig. 8. Dislocation substructure formed at initial stage of deformation at $1625^{\circ} \mathrm{C}$ under initial stress $10 \mathrm{MPa}$.

at steady state. However, no distinct subgrain boundaries or polygonization phenomena are observed. The dislocation density calculated from etch pits at $1625^{\circ} \mathrm{C}$ reached the order of $10^{8} / \mathrm{m}^{2}$ at inflection point and $10^{10} / \mathrm{m}^{2}$ at steady state.

\subsection{Creep at initial stage}

\section{Discussion}

It is generally accepted that the strain rate $\dot{\varepsilon}$ caused by movement of dislocations can be expressed by the following equation:9)

$$
\dot{\varepsilon}=\rho b v
$$

where $\rho$ is mobile dislocation density, $v$ is dislocation velocity and $b$ is Burgers vector. Usually, the dislocation velocity is assumed to be proportional to $\sigma^{m} \exp (-Q / R T)$ where $Q$ is activation energy and $T$ is temperature. By assuming that dislocation multiplication process relates to the crossing-over of dislocation dipoles and is dependent to $\sigma^{n^{\prime}}$, Haasen et al.7),10) established a theory to explain the sigmoidal creep behaviors of crystals with diamond structure. It shows that the dislocation density at inflection point $\rho_{\text {in }}$ can be expressed as $\rho_{\text {in }} \propto \sigma^{2}$. Combining these relations into Eq. (1) the creep rate at inflection point can be obtained as

$$
\dot{\varepsilon}_{\mathrm{in}}=C_{1} \sigma^{m+2} \exp (-Q / R T)
$$




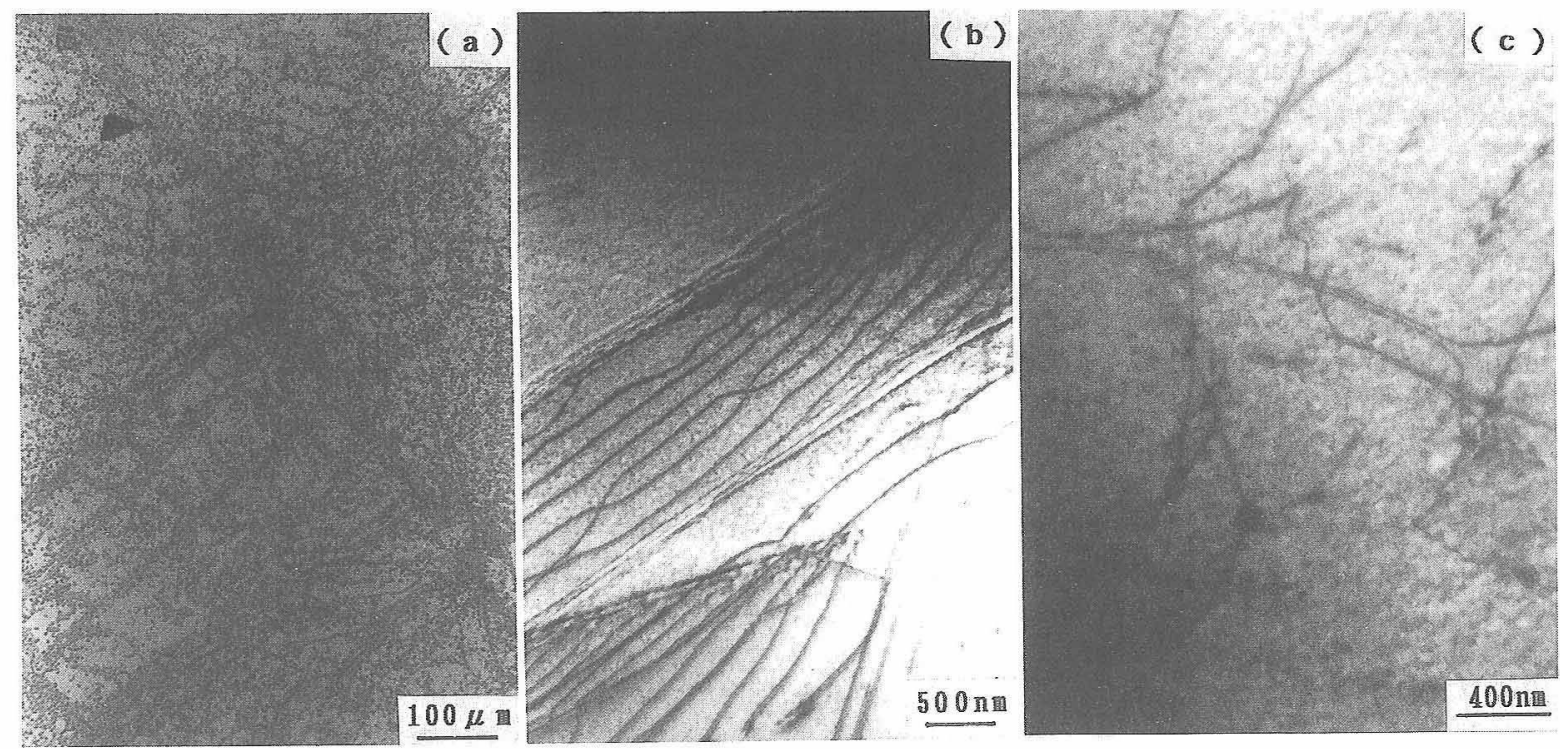

Fig. 9. Dislocation substructure at steady state at $1675^{\circ} \mathrm{C}$ under $8 \mathrm{MPa}$ observed by (a) etch pits in optical microscopy, (b) and (c) by TEM.

$$
1 / t_{\text {in }}=C_{2} \sigma^{m+n^{\prime}} \exp (-Q / R T)
$$

where $C_{1}$ and $C_{2}$ are constants, $n^{\prime}$ is the stress exponent for the dislocation multiplication. Obviously the creep rate depends mainly on the dislocation density and velocity. Whereas, $t_{\text {in }}$ relates to the process of dislocation multiplication additional to the dislocation velocity.

Comparing the experimental results, as shown in Figs. 2 to 6 , with the above equations it is found that the deformation of $\mathrm{MgO}$ crystal compressed with $\langle 100\rangle$ axis can be described by these equations. This indicates that the rise in creep rate at initial stage was predominantly caused by dislocation multiplication. The values for activation energy calculated from Eqs. (2) and (3) fall within a comparatively narrow range. The average value of stress exponent, $n(=m+2)$, of creep rate 3.4 as shown in Fig. 2 , indicates that dislocation velocity at the inflection point proportional to $\sigma^{1.4}$. Thus from the average value of stress exponent for $t_{\text {in }}, m+n^{\prime}=1.8$, as shown in Fig. 5 , it is known that the dislocation multiplication process at inflection point relates to $\sigma^{0.4}$. This value is different from that reported for InSb which is unity. ${ }^{7)}$ The possible reason for the difference may arise from the difference in multiplication processes between crystals with the structure of fcc and bcc.

Based on the fact that only two longitudinal surfaces of a crept specimen were oppositely barreled and the other two remained unchanged, as shown in Fig. 7 , it is considered that slips are mainly confined to two orthogonal conjugate $\{110\}$ planes. Figure 8 shows the dislocation substructure developed at initial stage near the inflection point. The orientation of dislocation bands suggests the generated dislocations are mainly restricted to two orthogonal $\{110\}$ slip planes, which lie at $45^{\circ}$ to the loading direction. The dislocation traces on remained two $\{110\}$ slip planes, which obliquely intersect with the former, are less observed. This phenomenon may be understood based on the analyses made by Gilman ${ }^{11)}$ and Kear. ${ }^{12)}$ They showed that the dislocation intersections on the oblique $\{110\}$ planes would generate the sessile dislocations, while the dislocation interactions on orthogonal $\{110\}$ planes would not. Therefore, no barreling on the neighboring surfaces is probably due to the impediments from the sessile dislocations caused by dislocation interactions between oblique $\{110\}$ planes. Those interactions result in effective barriers to restrain dislocation's motion on oblique planes, leaving slips only on two orthogonal conjugate $\{110\}$ planes as the main process contributing to deformation. Therefore, the barreling was only confined to two surfaces.

On the other hand, the dislocation distribution on the orthogonal $\{110\}$ planes indicates that slips at initial stage are locally limited as shown in Fig. 8. It appears that in a given region only one of $\{110\}\langle 110\rangle$ slip systems operated predominantly and the conjugate one in others. The slips on two orthogonal $\{110\}$ planes may start at different parts of volumetric regions in a specimen, probably at different ends or at the same ends but opposite sides, respectively, ${ }^{13)}$ at the beginning of deformation. In such a way the dislocation intersections will be considerably avoided. This process is considered to be directly responsible for the remarkable increase in creep rate at the initial stage since dislocations can move relatively free with less intersection. Clearly, the increase in creep rate at initial stage is caused not only by the increase in dislocation density, but the processes related to the activation of slip systems and the way on which dislocation multiplication or interaction proceeds also have remarkable effects on deformation behavior. 
With the increase in dislocation density the regions where only a single slip system operated extended and the intersection of dislocations took place increasingly. ${ }^{14)}$ Then the velocity of mobile dislocations started to decrease because of the impediments caused by dislocation intersections. The rise of creep rate becomes slow. When the increase in dislocation density contributing to the rise in creep rate was totally offset by the decrease in dislocation mobility, the rise of creep rate would stop and the creep rate started to go down with further dislocation intersections. A peak of creep rate appears, which corresponds to the inflection point on creep curve as shown in Fig. 1. It is considered that at inflection point a balance between increase in dislocation density $(\rho)$ and the decrease in dislocation velocity $(v)$ is reached instantly. Stress or temperature, which may affect either $\rho$ or $v$ to cause a change in creep rate, can influence the time to attain the inflection point as shown in Fig. 5. However, the sigmoidal type of deformation characteristics will not be affected. This is verified in Fig. 6 showing normalized creep curves obtained at different experimental conditions. Taking off the influences of temperature and stress, the characteristics of deformation can almost be represented by an identical creep curve.

Since the deformation directly results from dislocation glide on two orthogonal $\{110\}\langle 110\rangle$ slip systems, the value of stress exponent near 3.4 at inflection point was considered just to reflect a combined stress dependence of both dislocation density and dislocation velocity. The values of activation energy measured at $t_{\text {in }}$, as shown in Figs. 3 and 4, mainly relate to the potential for a process of dislocation's movements on the periodic lattice.

\subsection{Creep at steady state}

The deformation mode shown in Fig. 7 indicates that the slips are primarily confined to two sets of orthogonal $\{110\}$ planes. It is the main reason that no distinct subgrain boundaries or polygonization are formed since the dislocation intersections on the orthogonal $\{110\}$ planes may not generate the sessile nuclei for subboundary.2) On the other hand, the influence of the dislocation interactions between the oblique planes which may form sessile dislocations is relatively less important in the present circumstances. ${ }^{12)}$ The substructure developed at steady state in Fig. 9(a) shows that dislocations are uniformly distributed and some diffuse slip bands of high density are formed. Their orientation suggests that the bands correspond to the straight slip trance at the initial stage arisen from the slips on two orthogonal conjugate $\{110\}$ slip planes as shown in Fig. 8. The wavy nature of the bands indicates that considerable dislocation cross-slip or climb took place at steady state. The tanglement in dislocation alignment, especially at the region within the bands or around, is probably caused by the dislocation intersections between the orthogonal $\{110\}$ planes. This is consistent with what Figs. 9(b) and (c) show that within the bands the dislocation cusps, dipoles and the pile-up are formed. Therefore, these debris are likely to be the main barriers to dislocation motion. ${ }^{11)}$

Since the jogs on edge dislocations are mobile on $\{100\}$ planes at present temperature range, $\left.{ }^{15}\right)$ their dragging to the moving dislocation should not be strong. They may move with the gliding dislocations. Only the jogs with the screw dislocations are less mobile. They may be left behead at the wake of the dislocations as dipoles or dislocation loops and cause dislocation pile-up. ${ }^{11)}$ These debris may be moved out through a process of climb as suggested by Brechet et al. ${ }^{16)}$ and Quesnel and Tsou. ${ }^{17)}$ Therefore, it is possible that the deformation at steady state involves the glide and climb, i.e. the dislocations glide under the dragging of jogs or cusps which may be annihilated by a process of climb. Since the influence of sessile dislocations and the polygonized subboundaries, which were formed in the deformation process performed at high stress ranges, ${ }^{2), 18), 19)}$ is supposed to be negligible here, all dislocations should, to some extent, be mobile even with some dragging from jogs or cusps. The annihilation of dislocations with opposite sign which contributes the deformation may occur during gliding course. The measured activation energy at steady state, $Q=282$ $\mathrm{kJ} / \mathrm{mol}$ on average as shown in Fig. 3, is close to the value for the extrinsic lattice diffusion of oxygen in $\mathrm{MgO}{ }^{20)}$ It suggests that climb motion is controlled by lattice diffusion of oxygen.

For the deformation which involves the climb and glide Eq. (1) can generally be rewritten as

$$
\dot{\varepsilon}=\rho b V_{\mathrm{cl}} \delta /(d / 2)
$$

where $V_{\mathrm{cl}}$ is climb rate, $\delta$ is the distance over which a dislocation moves after climbing a height of $d / 2$. When climb controls dislocation movement the relation in Eq. (4) results in $\dot{\varepsilon} \propto \sigma^{4.5}$ or $\dot{\varepsilon} \propto \sigma^{3} .{ }^{21), 22)}$ However, the value $n=2$, measured at present study, is different from the suggested models and the results obtained at high stresses. ${ }^{19), 21)}$ The main reason for the different stress response of creep rate is considered to relate to the difference in dislocation substructure. Since no polygonized subgrain boundaries, within which dislocations are unmovable unless the climb occurs to cause the annihilation, were formed at present condition, the movement of dislocation is relatively "easier" than those within the subboundaries. Therefore, the glide distance $\delta$ can be considered to equal to the distance which a dislocation can glide after climbing over an obstacle, rather than the radius of dislocation loops as in the suggested model, ${ }^{21)}$ i.e. $\delta$ should be limited by the spacing between tow successively occurred dislocation intersections. On the other hand, when the dislocation is uniformly distributed the climb height $d / 2$ in Eq. (4) can be approximately found from the following relation 


$$
\rho=1 / d^{2}
$$

At $1625^{\circ} \mathrm{C}, 8 \mathrm{MPa}$, the value of $\rho$, measured from etch pits, reaches the order of $10^{10}\left(\mathrm{~m}^{-2}\right)$, then $d / 2$ is in the order of $5 \times 10^{-6} \mathrm{~m}\left(\approx 10^{4} b, b=2.96 \AA\right)$. This value is much larger than the estimated climb height by Blum ${ }^{23)}$ in a range of $7 \times 10^{-10}$ and $1.3 \times 10^{-8}(\mathrm{~m})$ for the dislocation climbing in the cell boundary formed at $1700^{\circ} \mathrm{C}$ under $83 \mathrm{MPa}$. It indicates that the climb height $d / 2$ may be of an identical size of jogs here, rather than the spacing between two parallel slip planes for the dislocation aligned within the subboundary as supposed to be. These are considered to be responsible for the differences between the present measurement and the established models in the relation of creep rate and stress.

Furthermore, since the dislocation density is relatively lower than those crept at a high stress ${ }^{2)}$ and the dislocations are more "movable" than those within cell boundaries the stress dependence of dislocation density in the suggested models ${ }^{21), 22)}$ may not be followed in present circumstance. This may also have an effect on the deformation behavior at steady state.

On the other hand, the difference in the deformation process between Stages I and III can be recognized from the way of dislocation's moving. In the former, the dislocations will keep moving without the affection of dragging by obstacles due to intersections until the annihilation occurs. At steady state the continuous movement of dislocations is replaced by a discrete slip among obstacles with a certain spacing and the moving dislocations are dragged by the debris. This difference is also reflected in the temperature dependence of creep rate. The different values of the activation energy suggest that the different processes for dislocation movement are involved at the initial stage and at the steady state.

The primary state of creep between Stages I and III is considered to relate to the establishment of a stable dislocation structure, in which the glide distance becomes unchangeable. Since no polygonized subgrain boundaries are formed and the barriers to dislocation movement only relate to the isolated cusps or dipoles on two orthogonal conjugate $\{110\}$ planes, it is possible that under such a condition the attainment to a stable structure takes longer time than that at high stress where the polygonized subgrain boundary is formed.2),19) This may be the reason for the long time to reach the steady state.

\section{Conclusions}

At low stress range, $\langle 100\rangle$ oriented $\mathrm{MgO}$ single crystals exhibited sigmoidal shaped creep curves. The deformation behavior at initial state followed Haasen's theories. The dislocation velocity was proportional to stress by $\sigma^{1.4}$.

The stress exponent and activation energy at inflection point were about 3.4 and $384 \mathrm{~kJ} / \mathrm{mol}$, respectively, which primarily reflected the dislocation gliding on two orthogonal conjugate $\{110\}$ planes with less effect of dislocation intersections. The increase in creep rate at initial stage was mainly related to the increase of dislocation density. Dislocation multiplication process was initiated from a volumetric region where only one slip system was operative.

At steady state no distinct polygonized subgrain boundaries were formed. The jogs or cusps on screw dislocations caused by dislocation intersections between two sets of orthogonal $\{110\}$ planes constituted main barriers to dislocation's movement. The creep behavior at steady state was considered to relate to a glide and climb process which shows the steady state creep rate is proportional to the stress by $\sigma^{2.2}$. The value of activation energy, $282 \mathrm{~kJ} / \mathrm{mol}$ on average, showed that the climb process related to the extrinsic lattice diffusion of oxygen ions.

Acknowledgements The authors wish to thank Professor Masaharu Kato, Tokyo Institute of Technology, for valuable discussions and comments on the dislocation movement and deformation mechanism.

\section{References}

1) R. B. Day and R. J. Stokes, J. Am. Ceram. Soc., 47, 493-503 (1964).

2) A. H. Clauer and B. A. Wilcox, J. Am. Ceram. Soc., 59, 8996 (1976).

3) W. Huther and B. Reppich, Phil. Mag., 28, 363-71 (1973).

4) T. G. Langdon and J. A. Pask, "High Temperature Oxides, Vol. 5-III", Ed. by Allen M. Alper, Academic Press, N.Y. (1970) pp. 53-127.

5) Y. Moriyoshi and T. Ikegami, "Advance in Ceramics, Vol. 10”, The Am. Ceram. Soc., Inc. (1985) pp. 258-74.

6) K. S. Ramesh, E. Yasuda and S. Kimura, J. Mater. Sci., 21, 4015-18 (1986).

7) E. Peissker, P. Haasen and H. Alexander, Phil. Mag., 7, 1279-303 (1962).

8) K. S. Ramesh, E. Yasuda and S. Kimura, J. Mater. Sci., 21, 3147-52 (1986)

9) W. G. Johnston, J. Appl. Phys., 33, 2716-30 (1962).

10) P. Haasen, Faraday Soc., 38, 191-200 (1964).

11) J. J. Gilman, "Progress in Ceramic Science, Vol. 1", Ed. by J. E. Burke, Pergamon Press (1961) pp. 146-99.

12) B. Kear, Phil. Mag., 4, 665-72 (1959).

13) S. M. Copley and J. A. Pask, J. Am. Ceram. Soc., 48, 139-46 (1965).

14) A. Gorum, W. Luhman and J. A. Pask, J. Am. Ceram. Soc., 43, 241-45 (1960).

15) C. O. Hulse, S. M. Copley and J. A. Pask, J. Am. Ceram. Soc., 46, 317-22 (1963).

16) Y. J. M. Brechet, J. R. Dryden and G. R. Purdy, Acta Metall., 8, 2261-65 (1989).

17) D. J. Quesnel and J. C. Tsou, Scripta Metall., 14, 935-38 (1980).

18) W. Huther and B. Reppich, Phil. Mag., 28, 363-71 (1973).

19) J. Dodsworth, C. Carter and D. Kohlstedt, "Advances in Ceramics, Vol. 6”, The Am. Ceram. Soc., Inc. (1983) pp. 7384.

20) Y. Oishi and W. Kingery, J. Chem. Phys., 33, 905-06 (1960).

21) J. Weertman, Trans. of the ASM, 61, 681-94 (1968).

22) F. R. Nabarro, Phil. Mag., 16, 231-37 (1967).

23) W. Blum, Z. Metallkde, 63, 757-63 (1972). 